\title{
On the Development Strategy of Health-Wellness Tourism in Panxi Region
}

\author{
Li Shu \\ Chengdu Polytechnic \\ Chengdu, Sichuan, 610041, China
}

\begin{abstract}
As China is vigorously promoting economic transition, and consumption upgrading, much of the attention is on the health-wellness tourism which is now embracing the great development. Panxi region has shifted its focus from vanadium, titanium-related industries to the tourism industry. This region is a health-wellness tourism destination with first-class domestic resources, geographical edges, transportation advantages, favorable climate and materials. Now it is necessary to develop both Panzhihua and Xichang, explore characteristics, develop theme communities, strengthen urban management and environmental protection, and create the all-weather first-class domestic health-wellness destination.
\end{abstract}

Keywords-Panxi region; health-wellness tourism; development strategy

\section{INTRODUCTION}

The five state ministries and commissions released the Guidance on Promoting the development of Health-related Tourism which puts forward to develop healthy tourism products, develop high-end medical services, develop traditional Chinese medicine services, develop rehabilitation services and develop leisure and health care service. It is expected to propel the development of healthy tourism industry and make the industry become more legal and standard by strengthening policy support. With the rapid development of the comprehensive health industry, people's travel habits and life concepts are undergoing profound changes. Tourism consumption is now more generated on leisure, health, and vacation rather than the sightseeing. Health-related tourism is now in the full swing.

\section{The GOlden Age OF Policy FOR HeAlth-Wellness TOURISM}

Issued in 2016, Opinions of the General Office of the State Council on Further Expanding Consumption in Tourism, Culture, Sports, Health Education and Training for the Aged proposed that health care tourism and medical tourism should be promoted with the establishment of national demonstration bases and the implementation of supportive policies in the first areas.

In the Development Planning of Five Economic Zones in Sichuan Province, issued by Sichuan government in 2016, five strategic positions were clearly put forward in the Development Planning of Panxi Economic Zone in the 13th Five-Year Plan, including the emerging growth pole characterized with innovative development of strategic resources, the national pilot zone of strategic resource innovation and development, the national hydropower development base of importance, the agricultural base with subtropical characteristics in Sichuan, and the nationally known holiday paradise of health-wellness tourism with beautiful sunshine.

Panzhihua, one city in Panxi region, has announced China's Development Planning of Health-Wellness Tourism Cities (2012-2020) in 2014. And Xichang, the other city, has proposed to develop an international holiday destination of health-wellness tourism with medicine and nursing combined.

\section{Connotation AND DenOtAtion OF HeAlth-WELLNESS TOURISM}

Up to now, there are plenty of studies about the connotation of health-wellness tourism with various characteristics. However, the similar recognition among them is that the health-wellness tourism, the combination of health care and travel, is a kind of experience which promotes tourists' physical and psychological health with health-care conception and activities running through their journeys. [1] The connotation of well-being tourism is embodied as follows. It is a tourist activity aiming at preserving one's health based on specific condition, especially the resource base, emphasizing the importance of ecology. It also reflects the culture and conception of health care, as well as tourism culture, so that cultural identity is an integration of natural ecology and humanistic connotation, guiding tourists to health maintenance.

As for tourism markets at present, relatively fledged healthwellness forms are those related to weather and climate, gardens and flowers, bank of the shores, mountains and forests, prairies and deserts, thermal spring, agriculture and farming, religion and folk-custom, fitness and medical treatment, etc.

\section{FAVORABLE BASIC CONDITION FOR HEALTH-WELLNESS TOURISM IN PANXI REGION}

As the combination of Panzhihua and Xichang, the Panxi region, located in the south-west in Sichuan province, has 20 counties and cities in administration, including Panzhihua Municipality and Yi Autonomous Prefecture of Liangshan. With geographical proximity, similar natural endowment and sightseeing resource, Panzhihua and Xichang are equipped with favorable foundation and condition for retreatment tourism, especially suitable for the development of health- 
wellness tourism with mountain, sunshine, motor homes, thermal spring, health care and medicine, etc.

\section{A. Richly endowed by a natural condition}

When compared with Chengdu, the capital city of Sichuan province, Panxi region enjoys superior air, unlimited sunniness, cool summer and warm winter with shining sun and delightful seasons for all year around. Comparing with Kunming in Yunnan province, there is a smaller difference in temperature between day and nights. And moderate altitude there makes it much more suitable for traveling throughout the year in comparison with Tibet. In conclusion, Panxi region deserves the high desirable recreational resort in Sichuan province and around the circumjacent area.

\section{B. Abundant tourism resources}

Being adjacent to Leshan Mountain, Mount Emei, Lijiang, Dali, Lugu Lake and other world-class scenic spots, Panxi gives full play to its regional advantages to enhance richness and layering in its tourist routes. Located in the western sunbelt in China, it is especially suitable to be visited in winter since there's neither typhoon nor cold-air outbreak, which is different from that in Hainan and Taiwan, two provinces in south China.

\section{Convenient communication}

Highway, railway and aviation have been interconnected in Panxi so far, with Highway G5 (Beijing-Kunming Expressway) and Chengdu-Kunming Railway running through, the construction of passenger transport line of Chengdu-Kunming Railway is about to start, and airports in Panzhihua and Xichang city, sending passengers to Chengdu, Chongqing and other cities.

\section{Abundant natural products}

With sufficient sunlight, Panxi region is in possession of abundant natural products. For instance, loquats in early spring, Dangdang chicken, bamboo fungus, navel oranges, mangos, bamboo eggs, bitter gourds, Chinese yam etc., are specialties in Panzhihua region, while Xichang region is abundant with garlic sprouts, fragrant rice, monkshood, black tartary buckwheat, kidney beans, tubers, pine nuts, black goats, pomegranates, JianChang ducks, white konjak, green prickleyash, pigs fed with canna edulis ker residue, navel oranges, semi-wool sheep, buckwheat tea, etc. In addition, moderate consumption level in Panxi makes it a befitting place to take a long recreational vacation.

\section{E. Inclusive immigrant culture}

Supported by long-term economic aid and accommodating numerous migrants from domestic and foreign provinces, Panxi has formed its special immigrant culture.[2] Residents settling down in Panxi have brought multi-culture connotation in and attracted a huge number of passengers in their home town to pay a visit to relatives and friends there. All the factors above can help Panxi expand its tourism market shares and improve its adaptability for senior tourists.

\section{ADVISES FOR HEALTH-WELLNESS TOURISM IN PANXI REGION}

\section{A. Development in collaboration to establish regional advantages}

For the moment, Panxi region is short of an introduction to the two cities' integrated advantages even though there are various tourism products setting up the city's image respectively. [3] Without integrated tourism resources, it's difficult to give expression to its advantages in regional cooperation. Although being known by many people in Sichuan province, Panxi's tourism industry still has a long way to go if it wants to become a famous destination of recreation throughout the country.

Panxi has a good foundation for cooperative development due to the tow cities' geographical adjacency, both sitting on an axis in south Sichuan, with similar resource endowment. As an old saying goes, if the two fight, they both losses; but if they go together, it is a win-win situation. In the fierce market competition, it is important for Panxi region to recognize that only binding and cluster-type development can help it establish strong regional attraction in Sichuan province, in the southwest, and even all over the country. It is strongly recommended that governments of two cities set up a unified tourism consultative and coordinating agency to evaluate the status of tourism resource, helping them get a clear understanding of their positions in Panxi tourism development to define their own roles. At the same time, the agency should implement an overall function planning and integrated marketing promotion with advantages from each other to form a unified image of health care destination, getting constellation efficiency as soon as possible.

\section{B. Dislocation competition with regional feature}

For the time being, scattered recreational projects, without sufficient characteristics, in the two cities cannot provide enough consumption guidance to tourists. As the author thought, they are supposed to develop distinctive tourist products, relying on their own resources, to realize dislocation competition and avoid homogeneity while they have similar natural resources.

Tourism resource in Liangshan city has been developed due to some historical reasons. There are four 4A-level scenic spots such as Qionghai-Lu Mountain, Luoji Mountain, Lugu Lake and Lingshan Temple, as well as Xichang Satellite Launch Base of 3A-level and national intangible cultural heritage such as the Torch Festival. However, there are only two 4A-level scenic spots of Ertan National Forest Park and the Gesala Original Ecology Area in Panzhihua city. Therefore, Liangshan city is recommended to design health-wellness tourism of mountains, religions and folk custom in addition to that of sunlight, while Panzhihua city is supposed to stress the importance of health-wellness tourism of sunlight, medicine and health care, motor homes, etc. 
C. Striving to develop rehabilitation-themed communities and service agencies and perfecting supporting facilities

At present, sightseeing is in the majority of tourism products and hotels are the uppermost living patterns. Longterm health-wellness tourism infrastructures mainly concentrate on some folk houses, Happy Farmhouses and lowgrade hotel. Recreational communities cannot take shape with few facilities for the elders and scattered agencies for health care and nursing.

As is known to all, the core of health-wellness tourism is preserving one's health, which is different from that of sightseeing, so that it should lead tourists to peace, to slow down, to stay and to live in the destination. On the one side, rehabilitation-themed communities and service agencies should be developed, and recreation marked be segmented, to satisfy different needs of tourist. On the other side, supporting facilities, including medical institutions, healthy recreational facilities, catering, fruits, flowers, eco-agriculture, etc., as well as rich healthy atmosphere should be taken into consideration in the planning and construction of recreational communities.

\section{Enhancing management of cities and scenic areas, advancing the level of civilization}

It is necessary for tourists to travel in an environment of cleanliness, safety and comfort. In spite of rapid development by leaps and bounds, when comparing with metropolis or some tourist cities in developed regions, the hub cities - Panzhihua and Xichang, are still facing problems and challenges, such as unreasonable congenital layout, traffic jam, poor sanitation, urgent public security, etc. In addition, management ability, development capability and quality of tourism practitioners are badly in need of improvement.

Xichang, for example, is a city with a large population, traffic jam, poor street sanitation and heavy pollution because of outdoor barbecue. The Lugu mountain scenic spot, which is adjacent to the famous Qionghai Lake outside Xichang city, is surrounded by landscape, lush vegetation and beautiful scenery, but poor pavement and sanitation, few toilets on the way to the mountaintop and little iconic scenery on the peak can lead tourists to disappointment. Planning and management on scenic areas and the whole city from the government is required to set up the conception that everyone is the tourism ambassador, and to create a clean, beautiful and friendly atmosphere for tourists.

\section{E. Strengthening environment protection and retaining valuable air resource}

There's not only opulent sunshine, but also superior air in Panxi region. It is obvious that tourists are thirsty for clean air since many major cities across the country are suffering from PM2.5. As the best-known recreational destination so far, Sanya in Hainan Province takes clean air of superior quality as its important selling point. As 2015 Liangshan Environment Quality Announcement shows, there are 361 effective monitoring days, in which 122 days have excellent environment (the first level standard), 233 days are in good condition (the second level standard), and 6 days have mild contamination (the second level standard) in one year of 365 days. As for that in Panzhihua, there are 91 days with excellent air, 267 days with the fine, and 4 days with mild contamination according to 2015 Panzhihua Environment Quality Announcement.

The author thinks that air of superior quality is an irreplaceable recreation resource of importance so that the two cities should take atmospheric environment protection into consideration when planning and conducting industrial distribution. For instance, the construction of PanGang Group's base in Xichang will not only majorly affect local air quality, but also influence tourists' choices of travel destination to some extent.

\section{F. Building all-season recreational market instead of those of migrant bird style and explosive growth of tourists in some season}

Winter and holiday are peak tourist time in Panxi area, which can trigger a plenty of social issues. For example, numerous tourists in winter lead to high hotel rates and shortage of tourism resources. Especially in holiday, crowds of tourists in scenic area bring soaring prices, urban congestion and difficult vehicle parking, leading to extremely poor travel experience. In contrast, tourism resources are in idle in offseason, and merchants in the area are forced to operation pressure.

The author thinks that issues above not only exist in Panxi area because of special features of its local tourism resources but also generally exist nationwide. With the promotion of paid vacation, it is imperative for tourists to travel in scattered places at any time. So that when vigorously promoting sunshine recreational travel in winter, Panxi area should also take advantage of its superior air and other tourism resources to develop tourist projects of all time, gradually guiding tourists to avoid the peak traveling season. For instance, tourists can visit Luoji Mountain in spring to admire alpine rose, spend the summer at leisure in Mountain Lu, Luoji Mountain and Ertan National Forest Park, come to enjoy and lost in red leaves in autumn, etc., supported by fruits, vegetables and local cuisine of four seasons. Step by step, a mature market of all-hour health-wellness tourism can be finally cultivated.

To sum up, Panxi region boasts favorable resources for health and wellness. Panzhihua and Xichang should seize the strategic opportunity that our country is vigorously developing health-wellness tourism, to make full use of the policy advantages, give full play to the resources, develop coordinately smart tourism, leisure tourism, sports tourism and research and study tourism, and jointly build a well-known health tourism destination in China.

\section{REFERENCES}

[1] Zhou Bo, Fang Wei. Comments on Domestic Wellness Tourism Research [J]. Tourism Forum:2012,01:40

[2] Hu Wenjie. On the Development of "Migrant Tourism” for the Elderly in PanxiDiqu [J]. Contemporary Tourism:2012,01: P93

[3] Tan Zhirong. Analysis of Regional Tourism Competition and Cooperation Mode and Strategy in Panxi Region[J]. Journal of Leshan Normal University: 2010,02:83 
[4] Xue Qunhui, Deng Yongjin. Strategies for Developing the Health Resources in the Minority Areas in Yunan [J]. Journal of Yunnan Minzu University (Social Sciences) 2011,28(5):245-249

[5] Dai Shouxin. On Shandong Health-related Tourism Innovation in the Context of All-for-one Tourism [J]. Tourism Overview,2019(05):135136
[6] Yan Hai. On the Construction of Health-related Tourism System under the Background of All-for-one Tourism Strategy -- Taking Pingliang City as an Example[J]. China Business Trade,2019(08):67-68. 